\title{
Involvement of NADPH oxidase in high-dose phenolic acid-induced pro-oxidant activity on rat mesenteric venules
}

\author{
WEN-YUAN DU ${ }^{1}$, YING XIAO ${ }^{2}$, JIAN-JING YAO ${ }^{1}$, ZHE HAO $^{3}$ and YU-BIN ZHAO ${ }^{1,3}$ \\ ${ }^{1}$ Medical and Electronic Experimental Center, The Traditional Chinese Medicine Hospital of Shijiazhuang \\ Affiliated to Hebei University of Chinese Medicine, Shijiazhuang, Hebei 050051; ${ }^{2}$ School of Chemical Engineering, \\ Shijiazhuang University, Shijiazhuang, Hebei 050035; ${ }^{3}$ The Third Hospital of Shijiazhuang, Shijiazhuang, \\ Hebei 050011, P.R. China
}

Received March 4, 2016; Accepted May 12, 2016

DOI: $10.3892 / \mathrm{etm} .2016 .3923$

\begin{abstract}
In the present study, we investigated the potential role of phenolic acids in initiating oxidative damage to microvascular endothelial cells and the underlying mechanism mediating the pro-oxidant action. Male Wistar rats received high doses of phenolic acid [caffeic acid (CA), salvianolic acid B (SAB), chlorogenic acid (ChA) or ferulic acid (FA)]. The creation of reactive oxygen species in mesenteric microcirculation endothelial cells and adherent leukocytes along with venules were assessed using intravital microscopy. The expression levels of NADPH oxidase subunits (Nox4 and p22 $2^{\text {phox }}$ in terminal ileum tissues were determined by western blot analysis. Intravenous injection of high-dose $\mathrm{ChA}$ or $\mathrm{CA}$ $(7 \mathrm{mg} / \mathrm{kg}$ ) markedly increased the peroxide production in the venular walls and upregulated the protein expression levels of Nox4 and $\mathrm{p} 22^{\text {phox }}$ in the ileum tissues, while the same dose of $\mathrm{CA}$ and $\mathrm{SAB}$ made no difference within the observation period. No changes were observed in the number of leukocytes adhering to the venular walls. High-dose ChA and FA led to an imbalance between the oxidant and antioxidant mechanism by boosting the expression levels of NADPH oxidase. Thus, we clarified the rationale behind the adverse effects of a herbal injection containing high levels of phenolic acid compounds.
\end{abstract}

\section{Introduction}

Phenolic acids are widely used in phytotherapy (1). Polyphenolic compounds commonly found in Chinese medicinal preparations have been reported to have several biological properties including antibacterial, detoxifying and

Correspondence to: Dr Yu-Bin Zhao, Medical and Electronic Experimental Center, The Traditional Chinese Medicine Hospital of Shijiazhuang Affiliated to Hebei University of Chinese Medicine, Shijiazhuang, Hebei 050051, P.R. China

E-mail: drzhyubin@163.com

Key words: phenolic acid, mesenteric microcirculation, NADPH oxidase, reactive oxygen species, drug safety antiphlogistic properties. Polyphenolic compounds such as chlorogenic acid (ChA), are commonly used as a characteristic marker for quality control in traditional Chinese medicine (2). However, there are studies on the side-effects associated with the intravenous administration of polyphenols in the clinical practice of Chinese herbal medicine (3). These adverse effects range from pruritus, asthma, shock, liver and kidney injury to death (4). Dual effect (efficacy and toxicity) of phenolic acid created major obstacles in the manner these Chinese herbal injections are utilized. The sources of these adverse effects and the mechanisms involved are creating increased interest among the experts. However, little is known in detail, and the current available data are inadequate.

In recent years, various biological and pharmacological properties of phenolic acids have led to researchers paying focus more attention on medical aspects of polyphenolic compounds. One of these properties is the antioxidant property of phenolic acids $(5,6)$. There are studies on antioxidants turning to pro-oxidants to accelerate lipid peroxidation and/or induce damage to the DNA of the cell $(7,8)$. It is believed that the pro-oxidation properties of plant-derived phenolics compounds may be important due to their anticancer activities as well as their apoptotic characteristics, rather than their antioxidation properties (9). Therefore, identifying how an antioxidant may turn into a pro-oxidant and play a biological role is of interest. It has been reported that higher concentrations of phenolic acid produced radicals, acting as a pro-oxidant, whereas lower concentrations of phenolic acid scavenged superoxide and hydroxyl radical in vitro (10).

A major source of the observed adverse side-effects of phenolic acids is their ability to cause oxidative damage to normal cells (11). This may explain the side-effects reported from patients after the injection of herbal medicines containing phenolic acids. These side-effects are more intense when the phenolic compounds are injected intravenously.

In the present study, we administered vayring phenolic acid stress in rat microvascular endothelial cells in vivo. By injecting high doses (enough to induce adverse effects) we examined the potential role of the oxidative stress. Phenolic acids investigated were as follows: i) caffeic acid (CA); ii) salvianolic acid B (SAB); iii) ChA; and iv) ferulic acid (FA) (Fig. 1). 
A

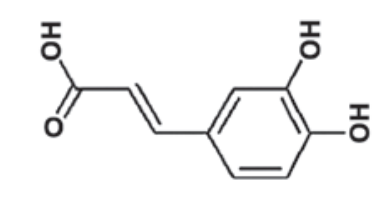

C<smiles>O=C(/C=C/c1ccc(O)c(O)c1)OC1CC(O)(C(=O)O)CC(O)C1O</smiles>

B<smiles>O=C(/C=C/c1ccc(O)c2c1C(C(=O)OC(Cc1ccc(O)c(O)c1)C(=O)O)[C@H](c1ccc(O)c(O)c1)O2)OC(Cc1ccc(O)c(O)c1)C(=O)O</smiles>

D<smiles>COc1cc(/C=C/C(=O)O)ccc1O</smiles>

Figure 1. Chemical structure of (A) ChA, (B) CA, (C) SAB and (D) FA. CA, caffeic acid; ChA, chlorogenic acid; SAB, salvianolic acid B; FA, ferulic acid.

\section{Materials and methods}

Animals. Thirty male Wistar rats, with a weight of 200-220 g, were obtained from the Animal Center of Peking University Health Science Center (certificate no. SCXK 2006-0008; Beijing, China). The rats were randomly assigned to weight-matched groups (6 rats in each group). The rats were housed in cages at the temperature of $22 \pm 2^{\circ} \mathrm{C}$ and with humidity equal to $40 \pm 5 \%$ under a 12 -h light/dark cycle. The rats received a standard diet and water ad libitum. The rats were fasted for $12 \mathrm{~h}$ prior to the experiment. The investigations conformed to the EU adopted Directive 2010/63/EU and the Guide of Peking University Animal Research Committee. Experiment protocols were approved by the Peking University Biomedical Ethics Committee Experimental Animal Ethics Branch (LA2011-38).

Experimental groups and drug administration. The rats were randomly assigned to weight-matched groups and anesthetized by intramuscular injection of 20\% urethane $(1 \mathrm{ml} / 100 \mathrm{~g}$ BW). Saline or phenolic acid was continuously infused via the left jugular vein catheter. CA, SAB, ChA and FA (National Institutes for Food and Drug Control, Beijing, China) were dissolved in the normal saline, and $7 \mathrm{mg} / \mathrm{kg}$ body weight was administered at a speed of $8 \mathrm{ml} / \mathrm{kg} / \mathrm{h}$ within $1 \mathrm{~h}$. The concentration of $7 \mathrm{mg} / \mathrm{kg}$ body weight was selected as it was 5 -fold higher than the recommended dose found in the instruction of Chinese herbal medicine injection protocols. Additionally, most of the reported adverse effects occurred around this dose. Animals in the control group received an equivalent volume of saline within the same period of time. In a series of experiments, the animals were administered with drug or saline only once, and subsequently were subjected to assessment of various parameters at the 120 -min time-point.

Microcirculatory observation. The surgical procedure was performed as previously described (12). The rats were anesthetized by intramuscular injection of $20 \%$ urethane $(1 \mathrm{ml} / 100 \mathrm{~g} \mathrm{BW})$. The abdomen was opened via incision of $25-30 \mathrm{~mm}$ in length. The ileocecal portion of the mesentery $(10-15 \mathrm{~cm}$ caudal) was gently exteriorized and mounted on a transparent plastic stage designed for the rat. The mesentery was kept warm and moist by continuous superfusion with saline solution at $37^{\circ} \mathrm{C}$. The mesenteric microcirculation was observed under an inverted microscope (DM IRB; Leica, Cologne, Germany) through the 20X objective lens. The mesentery was transilluminated with a $12 \mathrm{~V}, 100 \mathrm{~W}$, direct-current-stabilized light source. The microscopic images were obtained using a color video camera (JK-TU53H; Toshiba, Tokyo, Japan) mounted on the microscope, and the images were transmitted into a monitor (J2118A; TCL, Huizhou, China). The images were recorded using a Digital Video Disk videocassette recorder (DVR-R25; Malata, Xiamen, China). Single unbranched venules (30-50 $\mu \mathrm{m}$ in diameter; $200 \mu \mathrm{m}$ in length) were selected for investigation (12).

Microcirculation examinations were initiated after $10 \mathrm{~min}$ baseline observation. Adherent leukocytes were defined as cells that attached to the same site for $>10 \mathrm{sec}$ as determined from a replay of the video images. The number of adherent leukocytes along venules (30-50 $\mu \mathrm{m}$ in diameter and $200 \mu \mathrm{m}$ in length) that were randomly selected from the videotape images were counted at baseline (before infusion), and 40, 80 and 120 min after the infusion and expressed as the number per $200 \mu \mathrm{m}$ of venule length (12).

To monitor the oxidant stress in the venular walls, the oxidant-sensitive fluorescent probe dihydrorhodamine 123 (DHR 123; Molecular Probes, Eugene, OR, USA) was topically applied to the mesenteric surface $(10 \mu \mathrm{mol} / \mathrm{l})$ just $5 \mathrm{~min}$ before the observation. Fluorescence images were recorded at baseline (before infusion), and 40,80 and $120 \mathrm{~min}$ after infusion with an inverted fluorescence microscope (DM IRB; Leica) under 455-nm excitation light, and the fluorescence intensity of venular walls (Iv) and extravenular interstices (Ie) was measured with Image-Pro Plus 5.0 software (Rockville, MD, USA), respectively. The differences between Iv and Ie were determined for each time point, and the ratio of each value to the baseline was calculated (12).

Western blot analysis of Nox4 and P22 $2^{\text {phox }}$ protein expression. The terminal ileum tissues of rats were removed 120 min after infusion. Tissues were minced and homogenized on ice in lysis buffer $(150 \mathrm{mmol} / \mathrm{l} \mathrm{NaCl}, 50 \mathrm{mM}$ Tris- $\mathrm{HCl}, 1 \%$ Nonidet P-40 (NP-40) solution, and $0.1 \%$ sodium dodecyl sulfate (SDS), 

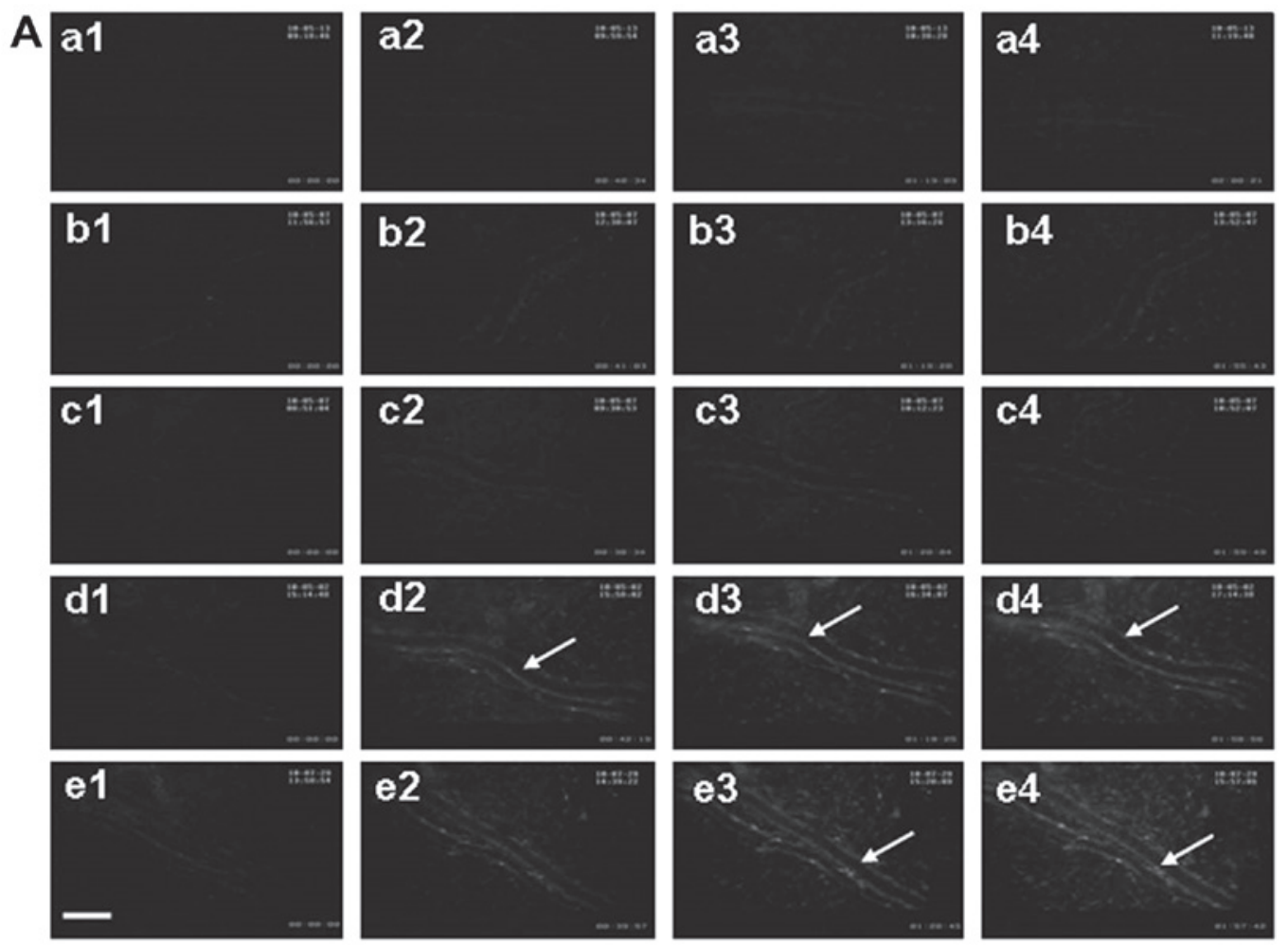

B

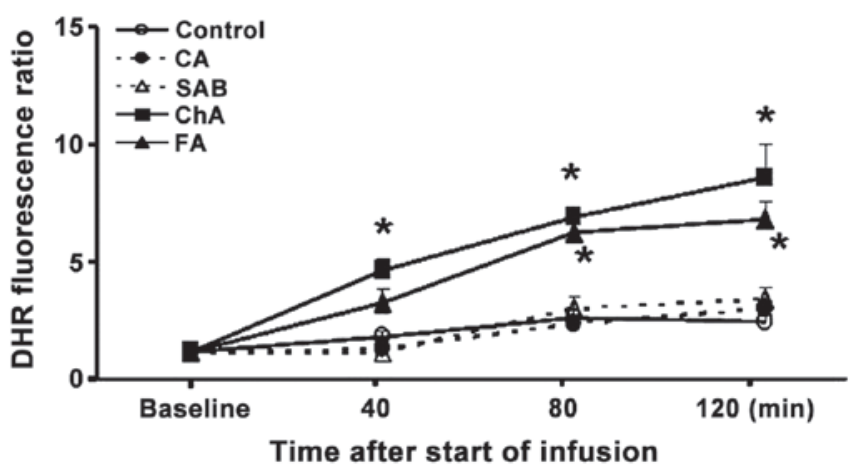

$\mathrm{pH}$ 7.4), and centrifuged for $10 \mathrm{~min}$ at $12,000 \mathrm{xg}$. The supernatant containing cytosol proteins was isolated and the total protein levels in the homogenates were quantified with a bicinchoninic acid (BCA) protein assay kit (Sun Biomedical Technology Co., Ltd., Beijing, China). The prepared samples in gel loading buffer [12.5 mmol/1 Tris-HCl, 2\% SDS, 10\% glycerol, $1.56 \%$ dithiothreitol (DTT), and $1 \%$ bromophenol blue, $\mathrm{pH}$ 6.8], were boiled for $5 \mathrm{~min}$. Equal amounts of proteins $(50 \mu \mathrm{g})$ for each sample were separated on a $10 \%$ SDS-polyacrylamide mini-gel at a constant voltage of $100 \mathrm{~V}$ for $2 \mathrm{~h}$. The proteins were transferred by electrophoresis at $30 \mathrm{~V}$ for $16 \mathrm{~h}$ to polyvinylidene difluoride (PVDF) membranes. The membranes were blocked for $1 \mathrm{~h}$ at room temperature in $5 \%(\mathrm{w} / \mathrm{v})$ non-fat dry milk in TBS-T $(10 \mathrm{mmol} / \mathrm{l} \mathrm{Tris-HCl}, 100 \mathrm{mmol} / \mathrm{l} \mathrm{NaCl}$, and $0.1 \mathrm{mmol} / 1$ Tween-20, pH 7.4). The membranes were then incubated overnight with rabbit polyclonal IgG against Nox4 [2 $\mu \mathrm{g} / \mathrm{ml}$; Abcam (Hong Kong) Ltd., Hong Kong, China] and p22 $2^{\text {phox }}$ (1:200, cat. no. sc-20781; Santa Cruz Biotechnology, Inc., Santa Cruz, CA, USA). After rinsing, the membranes were incubated with the horseradish peroxidase-conjugated secondary antibody
Figure 2. Effect of phenolic acids on DHR fluorescence intensity in rat mesenteric venular wall. (A) Representative images of the changes in DHR fluorescence intensity of the $\mathrm{H}_{2} \mathrm{O}_{2}$-sensitive probe DHR in the mesenteric venular wall in the (a) control, (b) CA, (c) SAB, (d) CA and (e) FA groups at (1) baseline, (2) 40, (3) 80 and (4) $120 \mathrm{~min}$, respectively. The arrow indicates DHR fluorescence on the venular wall; scale bar, $50 \mu \mathrm{m}$. (B) Time course of changes in the ratio of DHR fluorescence on the venular walls in different groups. Data are presented as means \pm SE of six animals. ${ }^{*} \mathrm{P}<0.05$ vs. control group. DHR, dihydrorhodamine 123; CA, caffeic acid; $\mathrm{SAB}$, salvianolic acid B; FA, ferulic acid.

(1:3,000; Santa Cruz Biotechnology, Inc.) for 2 h. Antibody labeling was detected by an enhanced chemiluminescence system and subsequently exposed to radiographic film. The optical density of bands were then visualized and normalized to that of $\beta$-actin (13).

Statistical analysis. Data were presented as mean \pm standard error (SE) and analyzed with the SPSS 17.0 statistical software package (SPSS Inc., Chicago, IL, USA). Differences were assessed with single-factor analysis of variance (ANOVA) followed by LSD tests and Tamhane's T2 tests. Statistically significant differences were indicated at $\mathrm{P}<0.05$.

\section{Results}

ChA and FA increases fluorescence intensity of DHR in the venular walls. The fluorescence intensity of DHR in the venular walls was examined in five groups at $120-\mathrm{min}$ time-points. Fig. 2A shows the representative fluorescent images of venules in various conditions with the 

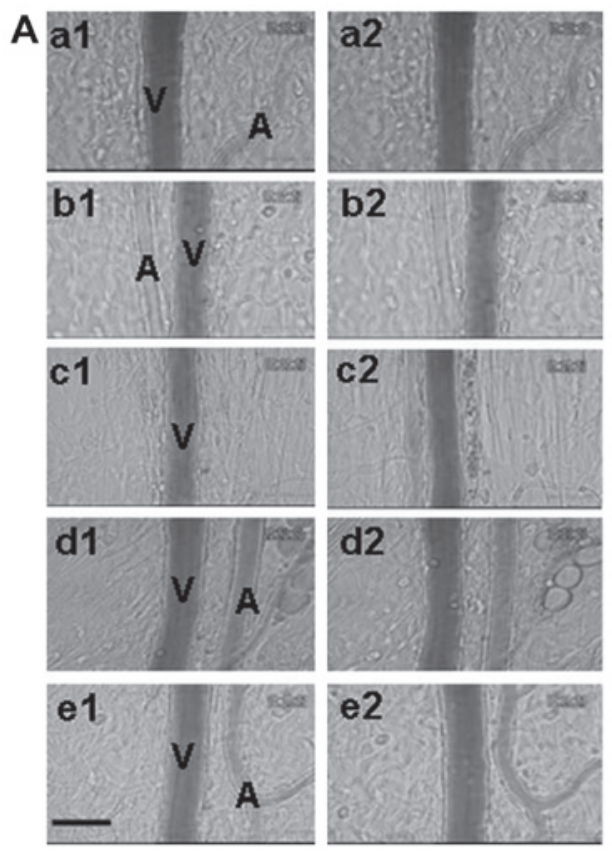
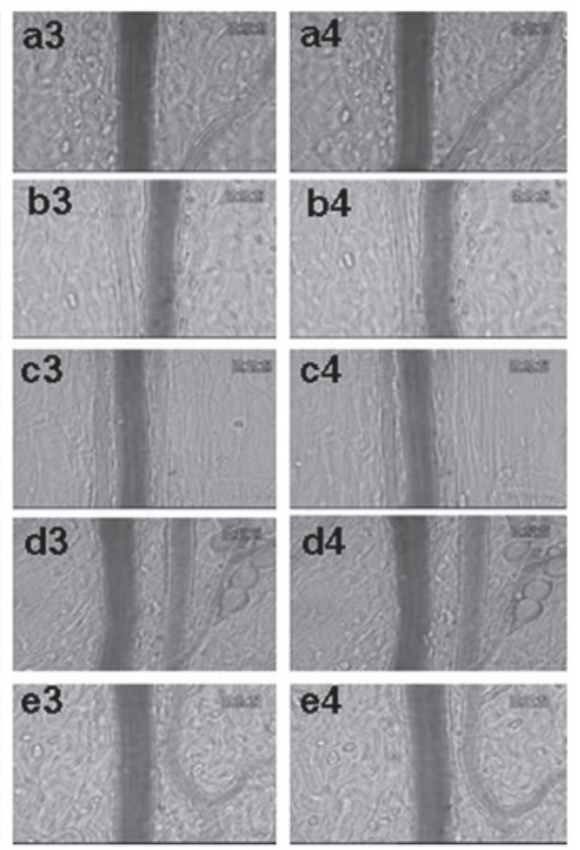

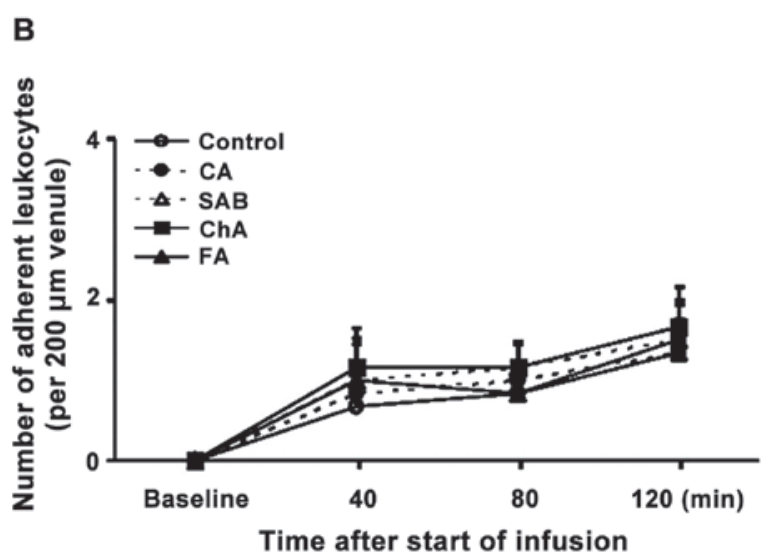

respective quantitative results shown in Fig. 2B. No DHR fluorescence was observed in rat mesenteric venular walls prior to infusion in the five groups (Fig. 2A-a1-e1), and low fluorescence intensity remained over the observation in the control group (Fig. 2A-a1-a4), as well as in the CA group (Fig. 2A-b1-b4) and SAB group (Fig. 2A-c1-c4). By contrast, ChA induced a pronounced DHR fluorescence in venular walls after infusion for $40 \mathrm{~min}$ (Fig. 2A-d2), $80 \mathrm{~min}$ (Fig. 2A-d3) and $120 \mathrm{~min}$ (Fig. 2A-d4) with significant differences as compared to the control group (Fig. 2B). Similarly, FA induced an obvious DHR fluorescence after infusion of $80 \mathrm{~min}$ (Fig. 2A-e3) and $120 \mathrm{~min}$ (Fig. 2A-e4) compared to the control group and slightly below the levels found in the ChA group. This indicated that $\mathrm{ChA}$ and FA were potentially able to induce the production of reactive oxygen species (ROS) from venules.

No change in the number of leukocytes adhering to the venular walls. Images of leukocytes adhering to the venular walls of the control (a), CA (b), SAB (c), ChA (d) and FA (e) groups were taken at baseline $0,40,60$ and $120 \mathrm{~min}$ after infusion (Fig. 3A). No adherent leukocytes were observed prior to the infusion in each group (Fig. 3A-a1-e1). Only a
Figure 3. Effect of phenolic acids on leukocyte adhesion to the rat mesenteric venular wall. (A) Representative images showing the effect of phenolic acids on leukocyte adhesion to the wall of a mesentery venule in the (a) control, (b) CA, (c) SAB, (d) CA and (e) FA groups at (1) baseline, (2) 40, (3) 80 and (4) $120 \mathrm{~min}$, respectively. V, mesenteric venule; A, mesenteric arteriole; scale bar, $50 \mu \mathrm{m}$. (B) Time course of changes in the number of leukocytes adhering to the mesenteric venules. The number of adherent leukocytes was expressed as the number of cells per $200 \mu \mathrm{m}$ of venule. Data are presented as means \pm SE of six animals. " $\mathrm{P}<0.05$ vs. control group. CA, caffeic acid; $\mathrm{SAB}$, salvianolic acid B; FA, ferulic acid.

small amount of adherent leukocytes were observed along the venular walls in the control group over the period of infusion (Fig. 3A-a2-a4). No significant differences were observed in the number of adherent leukocytes in the other groups of rats compared with the control group at each timepoint (Fig. 3A-b2-e4).

A quantitative analysis of the number of leukocytes adherent to venular walls at 120 min demonstrated that the number of adherent leukocytes in the control group was (1.5 \pm 0.43 per $200-\mu \mathrm{m}$ venule), CA group $(1.33 \pm 0.42$ per $200-\mu \mathrm{m}$ venule), $\mathrm{SAB}$ group ( $1.5 \pm 0.5$ per $200-\mu \mathrm{m}$ venule), ChA group (1.67 \pm 0.49 per $200-\mu \mathrm{m}$ venule) and FA group $(1.33 \pm 0.33$ per $200-\mu \mathrm{m}$ venule) (Fig. $3 \mathrm{~B})$.

ChA and FA increase Nox 4 and P22phox protein expression. We evaluated the role of NADPH oxidase in high-dose phenolic acid-induced ROS production from vasculature. We employed western blotting to determine the expression levels for the two subunits of NADPH oxidase, Nox4 and $222^{\text {phox }}$ (Figs. 4 and 5).

The expression of Nox4 and $\mathrm{p} 22^{\text {phox }}$ revealed no significant differences between the control, CA and SAB groups at the 120-min time-points examined. ChA increased the levels of 
A

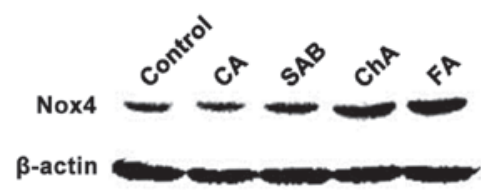

B

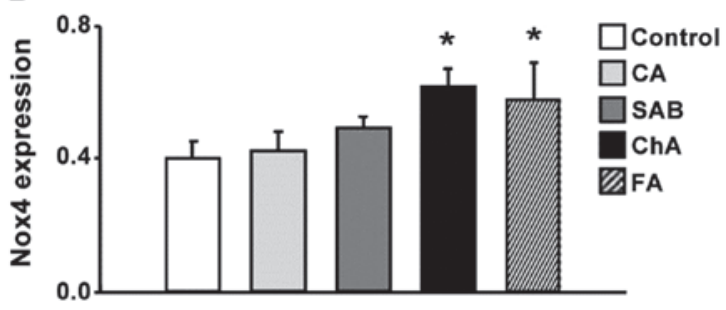

Figure 4. Protein expression of Nox4 in ileum tissues of rats. (A) Representative western blotting of Nox4. (B) Quantification of the western blotting shown in the upper panels. Data are presented as means $\pm \mathrm{SE}$ of four animals. ${ }^{*} \mathrm{P}<0.05$ vs. control group.

A

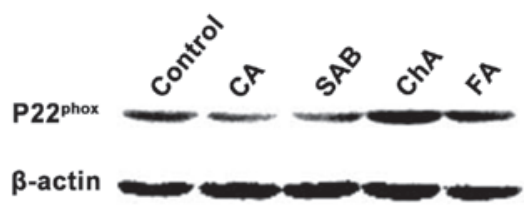

B

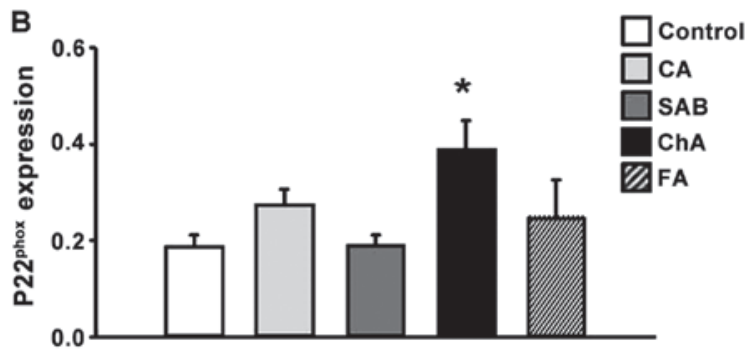

Figure 5. Protein expression of $\mathrm{P} 22^{\text {phox }}$ in ileum tissues of rats. (A) Representative western blotting of $\mathrm{p} 22^{\text {phox }}$. (B) Quantification of the western blotting shown in the upper panels. Data are presented as means $\pm \mathrm{SE}$ of four animals. " $\mathrm{P}<0.05$ vs. control group.

protein expression (for both proteins) compared to the control group, while FA only boosted the Nox4 expression and not the expression of $\mathrm{p} 22^{\text {phox }}$ (Figs. 4 and 5).

\section{Discussion}

The present findings have demonstrated that the intravenous injection of phenolic acids (ChA and FA) in high doses may create an imbalance in the oxidant/antioxidant mechanism, leading to oxidant stress and increased production of ROS in venular walls. High levels of Nox 4 and p $22^{\text {phox }}$ expression were observed in response to $\mathrm{ChA}$ and FA injections, indicating the involvement of NADPH oxidase in phenolic acid-induced oxidant stress. On the other hand, the injection of phenolic acids, used in this study, did no affect leukocyte recruitment in microvessels. This suggests that the phenolic acid-induced oxygen-free radicals are produced by endothelial cells and not neutrophils. Notably, pro-oxidation occurred only after the injection of high doses of ChA and FA, but not CA and $\mathrm{SAB}$ (with the same concentration) at $120 \mathrm{~min}$.
The $\mathrm{H}_{2} \mathrm{O}_{2}$-sensitive fluorescent probe DHR has been successfully employed for monitoring the oxidative stress and the measurement of dynamic alterations in intracellular $\mathrm{H}_{2} \mathrm{O}_{2}$ and other types of ROS levels in endothelial cell cultures. Similar results were obtained in other cell types (14-16). Previously, we established that low concentrations of ChA $(0.336$ and $1.68 \mathrm{mg} / \mathrm{kg})$ were not capable of inducing any DHR fluorescence intensity in rat microvasculature endothelial cells (17). The results of the present study show that oxidative stress in microvasculature was enhanced in the high-dose ChA and FA groups $(7 \mathrm{mg} / \mathrm{kg})$ starting from 40 and $80 \mathrm{~min}$ post-injection until $120 \mathrm{~min}$. This result suggested that phenolic acid-induced oxidative stress is dose-dependent. The finding was consistent with those of other reports $(10,18)$. The dose used in this study $(7 \mathrm{mg} / \mathrm{kg}$ body weight) was 5 -fold higher than the recommended dose identified in the instructions for the ChA dose in Qingkailing injection (a Chinese herb medicine). Available data indicated that in the majority of cases reporting adverse effects of ChA, victims were injected with a quantity close to this dose (4). In addition, the results showed that exposure to the same dose of CA and SAB did not trigger generation of ROS. Thus, the order of pro-oxidant effectiveness for phenolic acid family is $\mathrm{ChA}>\mathrm{FA}>\mathrm{CA}$ and $\mathrm{SAB}$.

The excessive generation of ROS is considered a pathological mechanism responsible for cell damage and organ dysfunction (10). Possible sources for the generation of ROS, include NAD(P)H oxidase, xanthine oxidase, and the uncoupling of endothelial nitric oxide synthase (eNOS) (19). In view of the critical importance of NADPH oxidase in generating the oxidative stress of dysregulated vascular redox environment (20), we investigated the members of NADPH oxidase family and explored the potential of this enzyme as the source of phenolic acids-induced ROS. It was found that high doses of ChA significantly increased the expression levels of Nox 4 and p22 $2^{\text {phox }}$ proteins in ileum tissue at $120 \mathrm{~min}$ after infusion. The FA group revealed a similar outcome for the expression levels of Nox4. Nox4 is present in all vascular cell walls and is significantly more abundant than any other Nox enzyme (21). Nox4 heterodimerizes with $\mathrm{p} 22^{\text {phox }}$ and causes enzyme functions $(13,22)$. The high levels of Nox4 and p22 $2^{\text {phox }}$ expression suggest that NADPH oxidase is involved in phenolic acid-induced vascular ROS production. Previously, it was shown that the nutritional ChA led to antioxidant effects by inhibiting the NADPH oxidase activity in aorta (23). The possibility of NADPH oxidase being involved in phenolic acid-induced redox reaction supports our findings. Results obtained from the intravenous injection of high doses of ChA or FA demonstrated that the pro-oxidant activity of the enzyme was significantly boosted while the antioxidant activity remained unchanged. Additionally, phenolic acids played a pro-oxidant role by mobilizing endogenous copper to increase the production of $\operatorname{ROS}(17,24)$.

Leukocyte adhesion to the venules may be the source of oxygen-free radicals released from the leukocytes (25). Nevertheless, leukocytes were not the primary source of ROS release since we did not detect any leukocytes adhering to the venular walls in the course of our observations. Thus, there is a possible involvement of other peroxidases and other mechanisms in vascular cells induced by phenolic acids. 
In conclusion, the present study findings show that intraveinal injection of high doses of phenolic acids particularly ChA and FA induced excessive ROS release from the venules, which suggests the double-edged sword property of phenolic acids as a drug. Our results provide new insight into understanding the reasons behind the observed adverse effects after the injection of phenolic acids. Clinicians are therefore required to be more diligent especially when a Chinese herbal injection containing high levels of phenolic acid content is to be applied by intravenous injection.

\section{References}

1. Huang WY, Cai YZ and Zhang Y: Natural phenolic compounds from medicinal herbs and dietary plants: potential use for cancer prevention. Nutr Cancer 62: 1-20, 2010.

2. Huang FH, Zhang XY, Zhang LY, Li Q, Ni B, Zheng XL and Chen AJ: Mast cell degranulation induced by chlorogenic acid. Acta Pharmacol Sin 31: 849-854, 2010.

3. Li Q, Zhang XY and Chen GS: Adverse effect and mechanism of chlorogenic acid in clearing heat and detoxication traditional Chinese medicine injections. Chin JMAP 26: 555-558, 2009.

4. Yuan Q, Wang L, Cheng L, Cui XH, Zhong DK, Li YY, Shang HC, Zang Bl and Li YP: Adverse drug reactions and adverse events of 33 varieties of Traditional Chinese Medicine Injections on the National Essential Drugs List (2004 edition) of China: An Overview on published literatures. Chin J Evid-based Med 10: 132-139, 2010

5. Taubert D, Breitenbach T, Lazar A, Censarek P, Harlfinger S, Berkels R, Klaus W and Roesen R: Reaction rate constants of superoxide scavenging by plant antioxidants. Free Radic Biol Med 35: 1599-1607, 2003.

6. Roche M, Dufour C, Mora N and Dangles O: Antioxidant activity of olive phenols: mechanistic investigation and characterization of oxidation products by mass spectrometry. Org Biomol Chem 3 : 423-430, 2005

7. Azmi AS, Bhat SH and Hadi SM: Resveratrol-Cu(II) induced DNA breakage in human peripheral lymphocytes: Implications for anticancer properties. FEBS Lett 579: 3131-3135, 2005.

8. Fukuhara K, Nagakawa M, Nakanishi I, Ohkubo K, Imai K, Urano S, Fukuzumi S, Ozawa T, Ikota N, Mochizuki M, et al: Structural basis for DNA-cleaving activity of resveratrol in the presence of Cu(II). Bioorg Med Chem 14: 1437-1443, 2006.

9. Hadi SM, Asad SF, Singh S and Ahmad A: Putative mechanism for anticancer and apoptosis-inducing properties of plant-derived polyphenolic compounds. IUBMB Life 50: 167-171, 2000.

10. Jiang Y, Kusama K, Satoh K, Takayama E, Watanabe S and Sakagami H: Induction of cytotoxicity by chlorogenic acid in human oral tumor cell lines. Phytomedicine 7: 483-491, 2000.

11. Rakshit S, Mandal L, Pal BC, Bagchi J, Biswas N, Chaudhuri J, Chowdhury AA, Manna A, Chaudhuri U, Konar A, et al: Involvement of ROS in chlorogenic acid-induced apoptosis of Bcr-Abl ${ }^{+}$CML cells. Biochem Pharmacol 80: 1662-1675, 2010.
12. Wang MX, Liu YY, Hu BH, Wei XH, Chang X, Sun K, Fan JY, Liao FL, Wang CS, Zheng J, et al: Total salvianolic acid improves ischemia-reperfusion-induced microcirculatory disturbance in rat mesentery. World J Gastroenterol 16: 5306-5316, 2010.

13. Collins-Underwood JR, Zhao W, Sharpe JG and Robbins ME: NADPH oxidase mediates radiation-induced oxidative stress in rat brain microvascular endothelial cells. Free Radic Biol Med 45: 929-938, 2008

14. Yuan Q, Liu YY, Sun K, Chen CH, Zhou CM, Wang CS, Li A, Zhang SW, Ye ZL, Fan JY, et al: Improving effect of pretreatment with yiqifumai on LPS-induced microcirculatory disturbance in rat mesentery. Shock 32: 310-316, 2009.

15. Han JY, Miura S, Akiba Y, Higuchi H, Kato S, Suzuki H, Yokoyama $\mathrm{H}$ and Ishii $\mathrm{H}$ : Chronic ethanol consumption exacerbates microcirculatory damage in rat mesentery after reperfusion. Am J Physiol Gastrointest Liver Physiol 280: G939-G948, 2001.

16. Han JY, Horie Y, Fan JY, Sun K, Guo J, Miura S and Hibi T: Potential of 3,4-dihydroxy-phenyl lactic acid for ameliorating ischemia-reperfusion-induced microvascular disturbance in rat mesentery. Am J Physiol Gastrointest Liver Physiol 296: G36-G44, 2009.

17. Chang C, Li WH, Li PT, Wang F, Wu JR and Du WY: Methods for testing of chlorogenic acid safty involving in traditional Chinese medicine. CN patent 102,200,505. Filed March 23, 2011; issued September 28, 2011.

18. Zheng LF, Dai F, Zhou B, Yang L and Liu ZL: Prooxidant activity of hydroxycinnamic acids on DNA damage in the presence of $\mathrm{Cu}$ (II) ions: mechanism and structure-activity relationship. Food Chem Toxicol 46: 149-156, 2008

19. Touyz RM: Reactive oxygen species, vascular oxidative stress, and redox signaling in hypertension: what is the clinical significance? Hypertension 44: 248-252, 2004.

20. Dai DZ and Dai Y: Role of endothelin receptor A and NADPH oxidase in vascular abnormalities. Vasc Health Risk Manag 6: 787-794, 2010

21. Haurani MJ, Cifuentes ME, Shepard AD and Pagano PJ: Nox4 oxidase overexpression specifically decreases endogenous Nox4 mRNA and inhibits angiotensin II-induced adventitial myofibroblast migration. Hypertension 52: 143-149, 2008.

22. Katsuyama M: NOX/NADPH oxidase, the superoxide-generating enzyme: its transcriptional regulation and physiological roles. J Pharmacol Sci 114: 134-146, 2010.

23. Suzuki A, Yamamoto N, Jokura H, Yamamoto M, Fujii A, Tokimitsu I and Saito I: Chlorogenic acid attenuates hypertension and improves endothelial function in spontaneously hypertensive rats. J Hypertens 24: 1065-1073, 2006.

24. Azmi AS, Bhat SH, Hanif S and Hadi SM: Plant polyphenols mobilize endogenous copper in human peripheral lymphocytes leading to oxidative DNA breakage: a putative mechanism for anticancer properties. FEBS Lett 580: 533-538, 2006.

25. Kurose I, Suematsu M, Miura S, Fukumura D, Sekizuka E, Nagata H, Oshio C and Tsuchiya M: Oxyradical generation from leukocytes during endotoxin-induced microcirculatory disturbance in rat mesentery - attenuating effect of cetraxate. Toxicol Appl Pharmacol 120: 37-44, 1993. 